\title{
DOS PRIMEIROS AOS SEGUNDOS DOZE PRINCÍPIOS DA QUÍMICA VERDE
}

\author{
Adélio A. S. C. Machado \\ Departamento de Química, Faculdade de Ciências, Universidade do Porto, R. Campo Alegre, 687, Porto 4169-007, Portugal
}

Recebido em 29/7/11; aceito em 21/12/11; publicado na web em 23/3/12

\begin{abstract}
FROM THE FIRST TO THE SECOND TWELVE PRINCIPLES OF GREEN CHEMISTRY. The second 12 principles of Green Chemistry (Winterton, 2001) are presented and discussed to show how they press academic chemists to focus the invention of synthetic pathways more directly on industrial process development, allowing a quicker progress along the greenness chain and a softer implementation of Green Chemistry in the industrial practice of chemistry. The relationships between the two sets of principles are tentatively established and discussed to make easier their joint use. The net of connections shows the systemic nature of Green Chemistry.
\end{abstract}

Keywords: Green Chemistry; second 12 principles; greenness chain.

\section{INTRODUÇÃO}

O desenvolvimento da Química Verde (QV) para substituição da Química Industrial vigente passa pela identificação prioritária dos problemas mais críticos para o ambiente e saúde humana cuja resolução seja exequível por reformatação da Química - e por um esforço persistente de invenção de novas moléculas e respetivos processos de fabrico industrial, no âmbito da $\mathrm{QV}$, que possam ir substituindo com a "vantagem verde" os usados atualmente. Esta mudança exige, por parte dos químicos e engenheiros químicos, em geral, e dos químicos laboratoriais que desenvolvem novos métodos de síntese e produzem novas moléculas, em particular, não apenas conhecimentos sólidos no domínio da química tradicional, mas também consciencialização, ideias claras e pragmatismo sobre como inovar a química para concretizar a QV.

Neste contexto, os 12 princípios da QV, introduzidos por Anastas e Warner ${ }^{1}$ e amplamente divulgados (por exemplo, nesta revista já foram publicitados pelo menos quatro vezes, ${ }^{2}$ o que comprova o interesse que despertam - porque são simples, mas também motivadores), têm servido para a consciencialização dos químicos sobre variados aspetos da Química que requerem revisão com vista a reduzir os seus impactos negativos sobre a saúde humana e ecológica. Os referidos princípios proporcionam prescrições genéricas para concretizar a transição da Química atual para a QV e têm sido usados com êxito - embora sejam frequentemente invocados pelos investigadores da QV para justificar o seu trabalho sem quantificação, ou mesmo escrutinação semiquantitativa, realizadas com métricas adequadas, do grau de verdura efetivamente alcançado. Posteriormente, foi proposto por Winterton, ${ }^{3}$ no âmbito de uma análise mais ampla das relações da Química com a sustentabilidade e o desenvolvimento sustentável, ${ }^{4}$ um segundo conjunto de princípios, os chamados segundos 12 princípios da QV, dirigidos especialmente aos profissionais da Química Académica que divisam novas vias de sínteses - já que se focam no escalamento destas, requerido para implementar processos de fabrico para a respetiva concretização industrial, o campo onde realmente interessa obter verdura. Estes segundos 12 princípios não têm sido objeto de tanta atenção como os primeiros, não sendo ainda abordados mesmo nos mais recentes livros de texto de QV, ${ }^{5,6}$ mas merecem ser divulgados, quer por poderem contribuir para a consciencialização referida atrás e a adoção de uma mentalidade mais proativamente

e-mail: amachado@fc.up.pt dirigida à verdura pelos químicos laboratoriais, quer porque, se usados com intencionalidade por estes, podem facilitar aos químicos industriais e engenheiros químicos o trabalho de desenvolvimento do processo, tornando-o mais expedito e eficaz.

O primeiro e principal objetivo deste artigo foi proporcionar a desejável divulgação deste segundo conjunto de princípios da QV em língua portuguesa, com vista a incentivar o seu uso; um segundo objetivo foi estabelecer tentativamente a rede de interligações entre os dois conjuntos de princípios, cujo reconhecimento é importante para facilitar a sua aplicação sistémica por parte dos químicos.

\section{OBJETIVOS E ALCANCE DOS SEGUNDOS DOZE PRINCÍPIOS}

No Quadro 1 apresentam-se, mediante breves formulações, os segundos 12 princípios, ${ }^{3}$ que são numerados a partir de treze, na sequência dos primeiros 12, para evitar confusões. Em termos globais, este segundo conjunto de princípios apela aos químicos académicos que realizam investigação de laboratório sobre síntese de compostos para incluírem na sua atividade uma atitude proativa de atenção às caraterísticas de verdura (ou sua falta) das reações químicas que desenvolverem e/ou usarem nas vias de síntese. Tal atitude passa fundamentalmente pela prática de dois procedimentos: procurar realizar intencionalmente planeamento de trabalho laboratorial de base mais globalmente dirigido para a QV; depois, no desenvolvimento deste, implementar a obtenção de informações relativas à verdura das reações químicas que utilizarem nas sínteses que inventarem. Mais concretamente, pede-se aos químicos laboratoriais, primeiro, que privilegiem o estudo e desenvolvimento de química básica inovatória, dirigida à obtenção de vias de síntese mais verdes; segundo, a colheita e publicação de dados adicionais que permitam avaliar precocemente as caraterísticas de verdura das novas vias de síntese estabelecidas.

A adoção desta atitude poderá contribuir decisivamente para a consolidação do desenvolvimento verde de produtos e processos, porque a disponibilidade de informação do tipo indicado, à partida do trabalho de desenvolvimento, facilitará a avaliação do potencial das reações químicas estudadas no laboratório para serem escaladas com boas soluções técnicas e sem perda das suas caraterísticas verdes -e, por exemplo, permitirá aos profissionais do desenvolvimento do processo (engenheiros químicos e químicos de processo) obter com mais facilidade bons níveis de minimização de resíduos e de consumo de energia, quando as mesmas reações forem realizadas a 
Quadro 1. Os segundos 12 princípios da QV

13 - Identificação e quantificação dos coprodutos (subprodutos eventuai e resíduos)

Identificar os coprodutos e determinar as suas quantidades relativamente à do produto principal

14 - Obtenção de conversões, seletividades, produtividades, etc.

Para além do rendimento químico das reações de síntese, determinar métricas relevantes para a QV: seletividades, produtividades (eficiência atómica e similares), etc.

15 - Estabelecimento de balanços materiais completos para o processo Especificar, quantificar e contabilizar todos os materiais usados na obtenção do produto final, incluindo os auxiliares, nomeadamente os solventes

16 - Determinação das perdas de catalisadores e solventes nos efluentes Determinar as quantidades ou caudais dos fluxos de efluentes líquidos, sólidos, e gasosos e as concentrações de reagentes auxiliares neles

17 - Investigação da energética básica do processo

Avaliar e relatar as variações de entalpia das reações exotérmicas com o fim de alertar para eventuais problemas de libertação de calor com a mudança de escala

18 - Identificação de limitações quanto às transferências de calor e de massa Identificar fatores que afetem as transferências de calor e de massa no escalamento (velocidades de agitação ou de dispersão de gases, áreas de contacto gás-líquido, etc.)

19 - Visualização das reações sob a perspetiva dos engenheiros químicos Identificar e analisar pontos de constrição para o escalamento no desenvolvimento do processo industrial por estudo das alternativas de tecnologia disponíveis para o implementar e por meio de contactos com engenheiros químicos

20 - Consideração da globalidade do processo industrial ao seleccionar a química de base

Avaliar o impacto das alternativas possíveis de todas as variáveis de processo (matérias primas, natureza do reator, operações de separação, etc.) nas oções possíveis para a química de base; e realizar experiências com os reagentes comerciais que vão ser utilizados no fabrico

21 - Procura (desenvolvimento e aplicação) de medidas de sustentabilidade do processo

Avaliar quantitativamente, na extensão possível, o grau de sustentabilidade do processo industrial

22 - Quantificação e minimização do uso de "utilidades"

Dar atenção ao uso e minimização das "utilidades", e proporcionar informação que permita avaliar as respetivas necessidades, logo no início do desenvolvimento do processo, ao longo do escalamento

23 - Identificação de situações de incompatibilidade entre a segurança do processo e a minimização de resíduos

Dar atenção à segurança do processo a desenvolver com base na síntese laboratorial e alertar para eventuais restrições de segurança que limitem as condições da implementação desta à escala industrial

24 - Monitorização, registo e minimização dos resíduos produzidos na síntese laboratorial

Dar atenção pormenorizada e quantitativa aos resíduos produzidos na realização laboratorial da síntese, registando as suas quantidades e adotando procedimentos que conduzam à sua minimização

escala maior do que no laboratório. A disponibilidade precoce destes dados é importante para simplificar e agilizar as sucessivas etapas do escalamento da síntese, até à versão final adequada ao fabrico industrial, com manutenção da verdura - já que a verdura de uma via de síntese só pode ser cabalmente avaliada no contexto da sua utilização na prática industrial. Embora a obtenção da verdura à escala industrial envolva frequentemente compromissos entre fatores contraditórios, impostos por considerações técnicas, económicas ou comerciais (e não apenas químicas), a adoção do segundo conjunto de princípios da QV pelos investigadores laboratoriais simplificará a avaliação e comparação da verdura potencial das diversas alternativas de processos químicos, logo desde as primeiras atividades do desenvolvimento do processo, incluindo a fase preliminar de seleção do próprio produto; e potenciará a manutenção da verdura ao longo da "cadeia de verdura" da Química, esquematizada na Figura 1, essencial para a montagem de uma nova Indústria Química Verde, adequada para suportar o desenvolvimento sustentável, a partir da QV de laboratório. A cadeia de verdura deve ser percorrida de modo a não se perder verdura ao longo do percurso, pelo contrário, aumentando a verdura quando se notam lacunas nesta - por exemplo, procurando soluções técnicas no equipamento que permitam colmatar deficiências de verdura a nível de reagentes, de condições de realização das reações, etc.

\section{CADEIA DE VERDURA DA QUÍMICA}

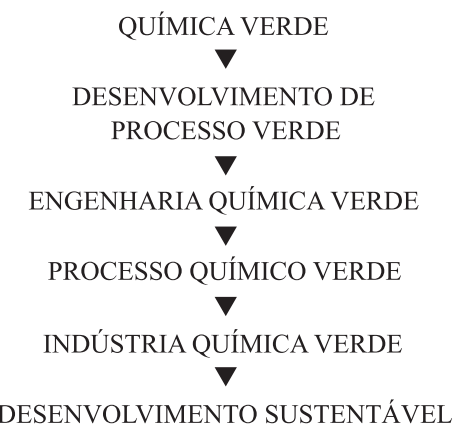

Figura 1. A cadeia de verdura da Química

\section{BREVE DISCUSSÃO DOS SEGUNDOS DOZE PRINCÍPIOS}

A seguir apresenta-se alguma informação sobre cada um dos segundos 12 princípios, complementar à inserida no Quadro 1, com o objetivo fundamental de promover a sua melhor compreensão e facilitar o seu embutimento na mente dos químicos laboratoriais de síntese - particularmente quando os princípios envolvem fatores mais ligados à engenharia química e química industrial, cujo conhecimento por eles pode ser mais superficial. Esta informação é relevante porque genericamente estes princípios adicionais são mais dirigidos ao processo industrial do que os de Anastas e Warner ${ }^{1}$ - e a avaliação da verdura no escalamento de uma síntese é muito mais fidedigna quanto ao nível final de verdura que se pode obter no processo industrial do que a realizada sobre a química de base.

\section{Princípio 13 - Identificar e, se possível, quantificar os coprodutos (subprodutos eventuais e resíduos)}

Este princípio, bem como os dois seguintes (e também o terceiro a seguir, embora de outro modo), apela aos químicos académicos para que sejam muito mais minuciosos quanto ao destino dos átomos dos reagentes que não são englobados no produto e a recolher informação sobre o que sucede com eles.

Os processos químicos raramente originam apenas o produto desejado, por mais que se aperfeiçoe a sua implementação, porque a especificidade das reações quase nunca é perfeita - em paralelo com o produto principal são quase invariavelmente obtidos produtos não desejados, os chamados coprodutos: eventuais subprodutos e/ou resíduos. A diferença entre subproduto e resíduo é ténue: os subprodutos são os compostos que encontram aplicação noutro processo, sendo, portanto, vendáveis ou utilizáveis; os resíduos não são aproveitáveis 
e têm de ser depostos no ambiente, podendo exigir tratamento prévio para os tornar inócuos - só dão prejuízos! Na realidade, a separação do produto e deposição no ambiente dos coprodutos de um processo químico pode exigir recursos especiais e ser muito dispendiosa, inclusive pode impedir a viabilidade económica do processo e, portanto, do produto - mesmo quando os resíduos se formam em quantidades pequenas.

Mais concretamente, em química académica tem-se o hábito de traduzir as reações por equações estequiométricas que evidenciem a formação do produto alvo, ignorando outras reações que podem ocorrer conjuntamente. Esta atitude implica que as equações estequiométricas sejam quase sempre uma aproximação, já que à escala industrial as reações secundárias ganham importância - e esta "imprecisão estequiométrica" provoca diminuição da eficiência de colocação dos átomos aportados pelos reagentes no produto (perdem-se em resíduos!). Na Figura 2, um químico de síntese, quando obtém um produto $\mathbf{P}$ a partir de reagentes $\mathbf{R}_{1}$ e $\mathbf{R}_{2}$, traduz tradicionalmente a preparação pela equação estequiométrica na parte superior da figura $\left(\mathbf{C}^{\mathbf{P}}{ }_{1}\right.$ representa um coproduto), quando o processo real pode ser algo mais complexo, por exemplo, o representado na parte inferior - em que se forma não só um segundo coproduto por decomposição do reagente $\mathbf{R}_{1}$, mas também um terceiro, o intermediário, $\mathbf{I}$, que não se converte completamente no produto, já que a segunda reação é de equilíbrio. Na prática industrial, a formação de estes outros coprodutos significa aumento da perda de átomos disponibilizados pelos reagentes, a não ser que aqueles possam ser separados e reciclados; também, a qualidade requerida ao produto pode exigir a sua separação para purificação deste. Estas operações de separação exigem equipamento e têm custos - se a pureza exigida ao produto for muito elevada, pode suceder que a síntese laboratorial seja industrialmente inviável, por razões técnicas (inexistência ou inexequibilidade de operação unitária adequada à separação) e/ou económicas (custos proibitivos).

\section{EQUAÇÃO ESTEQUIOMÉTRICA}

$$
\mathrm{R}_{1}+\mathrm{R}_{2} \rightarrow \mathrm{P}+\mathrm{C}_{1}^{\mathrm{P}}
$$

PROCESSO REAL

$$
\begin{aligned}
& \mathrm{R}_{1}+\mathrm{R}_{2} \rightarrow \mathrm{I} \leftrightarrows \mathrm{P}+\mathrm{C}_{1}^{\mathrm{P}} \\
& \downarrow \\
& \mathrm{C}_{2}^{\mathrm{P}}
\end{aligned}
$$

Figura 2. Exemplo da diferença entre a equação estequiométrica e o processo real

O caso anterior mostra que, a nível laboratorial, é importante identificar os subprodutos eventuais e resíduos e, se possível, determinar as suas quantidades relativamente à quantidade obtida do produto principal. Por outro lado, a ocorrência de vestígios dos coprodutos no produto pode ter variadas consequências negativas por exemplo, pôr em causa a sua utilização quando os requisitos de qualidade são estritos (nomeadamente em produtos farmacêuticos), afetar a respetiva estabilidade, etc.

A principal barreira quanto ao cumprimento deste princípio pelos químicos académicos de síntese é provavelmente a postura reducionista com que a química de laboratório é presentemente praticada e ensinada - em particular, a cinética e a termodinâmica são tratadas como ramos distintos, não se dando suficiente atenção às implicações das respetivas interrelações. Por exemplo, muitas reações são incompletas e não dão origem a um produto puro e, portanto, facilmente isolável; quando se força o deslocamento do equilíbrio para se aumentar a eficiência da reação, podem-se estimular reações laterais por via termodinâmica (por exemplo, variação de temperatura) ou cinética (por exemplo, aumento de concentração de reagente), incentivar a formação de coprodutos e frustrar, afinal, o aumento de eficiência atómica. Outro exemplo: quando o produto for obtido sob controlo cinético (por uma reação lenta), mas se puder formar um coproduto por uma reação secundária (paralela) favorecida termodinamicamente, o prolongamento do tempo de reação para aumentar a eficiência da síntese pode acarretar a formação de mais coproduto (o mesmo pode suceder quando o produto possa intervir numa reação consecutiva). Em todos estes casos, as operações de isolamento e purificação do produto são mais complexas e podem ter impactos negativos sobre o processo, nomeadamente económicos. Normalmente, o químico de síntese procura otimizar o rendimento da síntese por ajuste das condições experimentais, sem se deter muito nestes efeitos laterais: concentra a sua atenção no produto, esquecendo a natureza não linear da química ${ }^{7}$ (a seta usada nas equações químicas é desde logo um incentivo mental à linearização da visão sobre as reações químicas!). Esta atitude mental reducionista tem de ser revista para induzir a aplicação deste princípio, que faz um apelo aos químicos para "olharem para o lado" das reações químicas, e não apenas "para a frente" - para o produto.

\section{Princípio 14 - Obtenção de conversões, seletividades, produtividades, etc.}

Este princípio apela aos químicos académicos para que completem o prescrito no anterior com a obtenção de dados quantitativos sobre métricas de incorporação no produto dos átomos aportados pelos reagentes, bem como sobre grandezas cinéticas importantes para a realização industrial das reações.

A importância do primeiro aspeto resulta de o produto, mesmo que seja formado com rendimento elevado, poder ser produzido por meio de um processo globalmente ineficiente quanto à produtividade atómica - por dar origem a grande quantidade de resíduos. Esta situação é frequente, nomeadamente, se a via de síntese utiliza reagentes estequiométricos, isto é, reagentes usados em passos da via em que se introduzem alterações na molécula em construção, mas que não (ou quase não) aportam átomos para o produto, perdendo-se a maioria em resíduos (por exemplo, dióxido de manganês usado numa oxidação, que produz invariavelmente um sal de manganês(II) como resíduo). Os passos deste tipo são chamados estequiométricos (designação a contrastar com a de passos catalíticos, os prescritos preferencialmente pela QV - por exemplo, oxidações realizadas com oxigénio, por meio de um catalisador adequado). Os reagentes/ passos estequiométricos originam invariavelmente coprodutos, que podem ser variados mas que são sempre produzidos em quantidades elevadas (estequiométricas!) e requerem frequentemente separação e tratamento posterior para poderem ser reciclados ou depostos no ambiente. Por estas razões, para ajudar ao desenho do processo industrial, é desejável utilizar métricas mais informativas da "qualidade atómica" da via de síntese que o clássico rendimento químico, logo na descrição das vias laboratoriais - conversões, seletividades, produtividades (eficiência atómica e similares), etc. ${ }^{8}-$ e obter e incluir os seus valores no respetivo relato em artigos.

No mesmo contexto, interessa também obter e relatar as velocidades das reações, porque têm um papel essencial na "velocidade" de produção que pode ser atingida no processo industrial - esta grandeza, a chamada produtividade por unidade de tempo ou rendimento espaço-tempo, é o fator mais importante entre os que determinam o custo de produção. ${ }^{9}$ Por exemplo, no design de reatores define-se o rendimento espaço-tempo do reator em termos volúmicos, como a quantidade de produto obtida por unidade de tempo e por unidade de volume do reator. Esta grandeza é fulcral na conceção do reator quando a reação é lenta e obter um valor elevado para a velocidade 
de produção implica usar reatores de grande volume - o que significa maior tamanho e maior custo; ou na avaliação da performance que pode ser obtida com um reator já disponível, quanto ao tempo de utilização necessário para obter a quantidade de produto requerida que tem implicações nos custos (trabalho e "utilidades" de suporte - energia, água, luz). Em suma, os dados sobre velocidades de reação são essenciais para lidar com o fator tempo, crucial na atividade industrial, mas quase sempre esquecido na síntese académica. ${ }^{9}$

\section{Princípio 15 - Estabelecimento de balanços materiais completos para o processo}

Este princípio prescreve a utilização pelos químicos de síntese laboratorial de uma ferramenta tradicional da engenharia química, os balanços materiais (BM), para verificarem de modo global a manipulação e destino dos materiais em jogo numa via de síntese.

Todos os materiais usados numa reação de síntese e nas operações de purificação e isolamento do produto desejado devem ser identificados, quantificados e utilizados ao realizar o BM do processo laboratorial de síntese. A descrição deste deve incluir também a quantificação de todos os materiais auxiliares, usados na obtenção do produto final no estado de pureza que se pretenda atingir, nomeadamente os solventes. Se possível, o BM global do processo deve ser decomposto em duas componentes: BM da reação e BM das operações de separação e isolamento (work-up).

O estabelecimento de BM é importante para verificar que todos os materiais entrados foram contabilizados à saída - ou, se não foram, escrutinar porquê (por exemplo, porque se formaram compostos não identificados ou ocorreram perdas físicas na manipulação, que à escala industrial podem ter impactos negativos na saúde dos trabalhadores e até no ambiente). Os BM são muito usados pelos engenheiros químicos ao longo do desenvolvimento do processo e o seu fornecimento pelos químicos de síntese poupará o trabalho de obter a sua primeira versão - que tradicionalmente começa quase sempre pela recolha preliminar de dados em falta.

Em suma, no contexto da avaliação e melhoria da verdura atómica, os dados fornecidos por BM completos são importantes para aferir a eficiência da reação quanto ao aproveitamento dos átomos e minimizar a sua perda em resíduos.

\section{Princípio 16 - Determinação das perdas de catalisadores e solventes nos efluentes líquidos, sólidos ou gasosos}

Uma situação frequente é os BM revelarem perdas inesperadas, isto é, a ocorrência de materiais que não foram contabilizados, o que vulgarmente se deve à menor atenção prestada ao destino de materiais secundários, em especial solventes e catalisadores. Consegue-se obter uma avaliação mais completa e precisa das perdas destes nas reações por determinação direta das respetivas quantidades nos fluxos de efluentes líquidos, sólidos e, eventualmente, gasosos, libertados para ou a depor no ambiente, que fornece valores de maior confiança do que a simples pesagem dos solventes e catalisadores usados inicialmente e recuperados no fim do processo. Para isso têm também de ser determinadas as quantidades (volumes ou massas) dos referidos fluxos ou os seus caudais.

Este princípio é o último de um conjunto de quatro que globalmente visa obter, por parte dos químicos de síntese, uma visão muito mais pormenorizada do que a tradicional do que sucede aos átomos intervenientes nas reações químicas (ou que as suportam em substâncias auxiliares ) - com vista a maximizar a produtividade atómica. Assim, estes quatro princípios têm como objetivo a Química - em contraste, os dois seguintes dirigem-se à Física: apelam aos químicos para dar atenção à importância da física na realização das reações químicas nas condições industriais, algo sistematicamente ignorado no laboratório, na química a pequena escala. Por exemplo, transferir uns gramas de um reagente do respetivo frasco para o balão onde se vai realizar uma reação no laboratório é uma operação física que geralmente não levanta qualquer problema logístico - mas carregar um grande reator industrial com centenas de quilos de reagentes é um problema físico (mecânico) que requer equipamento, energia e trabalho, demora tempo, etc.

\section{Princípio 17 - Investigação da energética básica do processo para identificar reações exotérmicas potencialmente perigosas}

A manipulação da energia (e seus custos) é realizada pelos químicos laboratoriais com total esquecimento do seu significado na prática industrial: por exemplo, quando precisam de aquecer o meio da reação, nomeadamente para aumentar a velocidade de reação, usam equipamento adequado disponível no laboratório (bico de gás, manta elétrica, etc.), não se preocupando em saber quanta energia gastam; se precisam de arrefecer, usam, por exemplo, água (nomeadamente nos condensadores empregues nas destilações), esquecendo o respetivo volume eliminado pelo esgoto (perdido!). Em ambos os casos, o custo é esquecido - quem paga as contas é o diretor do departamento ou faculdade! Em contraste, na Indústria Química é prestada cada vez mais atenção ao consumo, poupança e conservação de energia - já que esta indústria é um consumidor voraz deste importante fator de produção, ${ }^{10} \mathrm{o}$ que implica fortes impactos negativos sobre o ambiente ${ }^{11}$ (uma situação semelhante também ocorre com a água).

Por outro lado, salvo raras exceções, a realização de reações químicas no laboratório, feita em pequena escala, não envolve grandes problemas de segurança decorrentes da libertação de calor, pelo que esta questão é também frequentemente ignorada - apenas nos casos de certas reações fortemente exotérmicas é que se presta atenção à necessidade de se proceder ao arrefecimento do meio de reação, após o período de indução inicial, para não se perder o controlo da situação. No entanto, a dissipação de calor depende fortemente da escala, pelo que as situações laboratorial e industrial podem ser completamente diferentes - este é outro aspeto frequentemente ignorado no ensino da química académica, pelo que se inclui uma abordagem sumária do assunto $^{12}$ no material suplementar. Como o calor gerado num reator $\left(\mathrm{Q}_{\mathrm{R}}\right)$ depende do volume $(\mathrm{V})$, mas a capacidade de transferir calor para o exterior $\left(\mathrm{Q}_{\mathrm{T}}\right)$ depende da área $(\mathrm{A})$, o aumento de dimensão dificulta a transferência de calor - e favorece o aquecimento, o que pode afetar as métricas de massa da reação (conversões, seletividades, etc., em suma, a produtividade).

Outro aspecto deste problema diz respeito à segurança. Quando a capacidade para transferir o calor para o exterior for inferior ao calor libertado pela reação química, $\mathrm{Q}_{\mathrm{T}} / \mathrm{Q}_{\mathrm{R}}<1$, o calor que se mantém no recipiente vai aquecendo o meio, a temperatura sobe, o que acelera a reação e liberta mais calor, e assim sucessivamente: estabelece-se um ciclo de retroação positiva, podendo perder-se facilmente o controlo da situação - e ocorrer uma expulsão violenta do meio de reação para o exterior ou uma explosão. Uma fração apreciável dos desastres industriais com reatores envolve situações deste tipo, que ocorrem principalmente em reações de polimerização (em que se formam muitas ligações químicas) e reações de nitração, sulfonação, etc. (em que se formam ligações químicas fortes) - em ambos os tipos, a formação de ligações é responsável pela libertação de quantidades elevadas de calor. ${ }^{13}$

Em suma, ao aumentar a escala do laboratório para a indústria, a razão "área superficial/volume" dos reatores aumenta segundo (A/V), ou seja (1/L), isto é, a área aumenta menos que o correspondente volume e, por isso, na prática industrial, podem surgir limitações significativas quanto à transferência do calor libertado nas reações exotérmicas para o exterior que não são sentidas no laboratório. Por 
isso, se o químico fornecer dados sobre a energética de uma reação exotérmica, os profissionais que realizam o escalamento do processo ficam alertados sobre eventuais problemas de libertação de calor e podem desde logo dirigir a conceção do reator para modelos com razão (A/V) elevada para evitar os impactos negativos de um aquecimento excessivo, não só na segurança, mas também na eficiência da formação do produto, através da deterioração das métricas de massa.

\section{Princípio 18 - Identificação de limitações quanto às transferên- cias de calor e de massa}

Além da libertação de calor intrínseca nas reações de síntese, pode haver outros fatores que afetem as transferências de calor e de massa e influenciem o decurso da reação e a qualidade do produto obtido quando do aumento de escala, por exemplo, a velocidade de agitação, a rapidez de dispersão de gases, a extensão da área de uma superfície de contacto gás-líquido (tamanho das bolhas de gás), etc. Esses fatores devem ser identificados e relatados, para que a sua influência na exequibilidade e eficácia do aumento de escala possa ser avaliada - para impedir eventuais efeitos nocivos na segurança do processo, qualidade do produto, etc.

Este princípio e o anterior visam consciencializar os químicos para o papel da Física na realização das reações químicas à escala industrial, que implica frequentemente barreiras a vencer que não se fazem sentir no laboratório - mas que têm de ser consideradas em conjunto com a Química, que foi objeto dos quatro primeiros princípios. Os três princípios seguintes envolvem facetas de natureza diferente: prescrevem atenção $\mathrm{a}$ factos que dizem respeito à mudança de postura mental em jogo quando se passa do laboratório para a execução do processo químico na atividade industrial.

\section{Princípio 19 - Visualização das reações sob a perspetiva dos engenheiros químicos ou de processo}

Embora o fabrico de um composto tenha como componente fundamental a reação de síntese e o reator constitua o cerne do respetivo processo industrial, este envolve geralmente outras operações, quer a montante (aquecimento de reagentes, eliminação de impurezas que envenenam catalisadores, etc.), quer a juzante (separações, purificação do produto, etc.) - estas operações são tão importantes para o processo como as reações químicas e envolvem custos significativos. No entanto, os químicos de laboratório não lhes dão grande importância, já que tendem a restringir a sua atenção ao produto que visam obter e às respetivas reações de síntese. Também, outro aspeto geralmente esquecido é a economia do processo (diminuição dos custos para otimizar o lucro!), que tem de ser aferida repetitivamente ao longo do seu desenvolvimento - presentemente, a diminuição de custos envolve facetas que ainda não são objeto de suficiente atenção nos cursos de Química, por exemplo, a minimização da energia e dos resíduos.

A implementação da Química a nível industrial é muito mais complexa do que no laboratório, o que acarreta não só desvantagens mas também oportunidades. Em face da enorme complexidade da Química Industrial, na prática, não é possível avançar para o desenvolvimento eficaz da QV sem preparar os químicos de laboratório para uma colaboração apertada com os engenheiros químicos - o que passa também por uma maior abertura da Química, ensinada nos cursos de Química, a processos e técnicas usados na Química Industrial. Por exemplo, a realização industrial de uma reação química pode ser feita de modos muito mais versáteis do que os habitualmente usados no laboratório; estes utilizam, quase sempre, apenas reatores de carga ou partida (balões, etc.) e, quando pretendem sintetizar um composto, se uma reação em que usam um determinado conjunto de reagentes não ocorre satisfatoriamente, em geral passam a outra com outros reagentes - não investigam processos alternativos de realizar a reação em outro tipo de equipamento, mais semelhante ao usado à escala industrial, por exemplo, reatores de fluxo com reciclagem de reagentes para operar em regime contínuo.

Os modos de realizar as reações químicas na indústria são variados, em resultado, por exemplo, da diversidade da natureza, configuração e estrutura dos reatores e das alternativas de tratamento dos produtos na mistura produzida (separações, reciclagem de reagentes, etc.). Esta variedade de fatores tem influência no resultado final da reação ou via de síntese, traduzido pela quantidade e caraterísticas do produto obtido - e alguns destes fatores podem ser importantes para a verdura do processo industrial. Estes factos tendem a ser esquecidos pelos químicos académicos, que, em geral, não prestam atenção a vários aspetos de grande importância para os engenheiros químicos, por exemplo, o regime do processo (cargas, fluxo contínuo, etc.), o desenho do reator, os modos de mistura de reagentes, as transferências de massa entre fases e de energia (ver princípio 18), etc. Se estes aspetos não forem devidamente considerados, podem ocasionar dificuldades e ineficiências no desenvolvimento do processo industrial.

Por isso, os químicos, quando estudam as reações químicas para servir de base a um processo industrial, devem tentar obter a perspetiva dos engenheiros quando procedem ao aumento de escala das operações - no mínimo, devem analisar a literatura técnica referente a casos semelhantes ou, mais desejavelmente, entrar em contacto com engenheiros químicos com experiência no campo e discutir com eles a via de síntese que têm em mente. Este esforço de "saltar" para a realidade da Química Industrial é importante para que os químicos adquiram capacidades para, por exemplo, identificar e analisar eventuais pontos de constrição que possam surgir no escalamento das reações químicas ao desenvolver o processo - mais concretamente para tentar caraterizá-los cabalmente e, na medida do possível, resolvê-los ainda na própria investigação laboratorial. Para isso, é importante que os químicos procurem adquirir conhecimentos sobre a natureza e problemas do escalamento (decorrentes da "grandeza do salto" entre preparar umas dezenas de gramas de composto num trabalho de laboratório que dura algumas horas e fabricar, de forma consistente, uns milhares de toneladas de composto por ano numa instalação industrial), as várias alternativas de tecnologia disponíveis, os aspetos benéficos e maléficos que determinam a respetiva verdura relativa, etc. - para obter a perspetiva dos engenheiros químicos sobre as reações químicas a usar no processo industrial.

\section{Princípio 20 - Consideração da globalidade do processo industrial ao seleccionar a química de base}

Os químicos de laboratório procuram estabelecer novas vias de síntese com maior eficiência, aferida pelos critérios habitualmente usados pela química académica, por exemplo, procuram maior seletividade e conversão; no entanto, o escalamento permite novas oportunidades - o que pode implicar critérios de avaliação adicionais. Na montagem de um processo químico há quase sempre diversas possibilidades alternativas para variáveis diversas: matérias-primas de base, reagentes usados na alimentação do reator, natureza deste, operações de separação do produto e coprodutos, operações complementares necessárias para obter o produto com o grau de pureza requerido, utilização da energia e das "utilidades", processos de recuperação de catalisadores e/ou solventes, tratamento e deposição de resíduos, etc. Quando no laboratório se investiga uma via de síntese para usar num novo processo, as alternativas possíveis de todas estas variáveis devem ser consideradas pragmaticamente com vista a determinar o seu impacto nas opções possíveis para a química de base. Também não se pode esquecer que a inovação introduzida na via laboratorial tem de ser escalada, o que na prática, se implicar um 
grande afastamento das condições vigentes na atividade industrial, pode exigir um esforço proibitivo em termos de tempo, custos, incerteza quanto à performance (por exemplo, no escalamento de um novo tipo de reator), etc. - o que tende a "travar" a inovação. Esta interação, de natureza complexa por envolver fatores económicos, logísticos, humanos, etc., condiciona fortemente a exequibilidade da inovação, um facto que o químico académico deve ter sempre em mente.

Quando se pretende inovar um processo bem estabelecido, isto é, mudar a respetiva química para melhorar a verdura, vale a pena analisar globalmente a tecnologia em uso com vista a introduzir modificações. Por exemplo, considerar a redução do número de passos usados para obter um reagente de alimentação do reator principal a partir de matérias-primas de base; ou, quando é usado um álcool na alimentação, que pode ser obtido por hidratação de uma olefina, que, por sua vez, pode ser obtida por cracking ou desidrogenação de um hidrocarboneto saturado proveniente do petróleo, considerar a possibilidade de usar como reagente de alimentação o próprio hidrocarboneto saturado.

No entanto, não se deve esquecer que a substituição de matérias-primas levanta numerosas questões, por exemplo, quanto aos resíduos, forma-se um novo fluxo de resíduos ao longo da cadeia de passos que constituem o novo processo? Que problemas de tratamento e utilização ou deposição levanta esse fluxo? Quanto ao processo, qual é o efeito da pureza do reagente de alimentação no desenvolvimento do processo - se é requerido um grau elevado de pureza, o processo tem viabilidade económica? Se tem, pode pôr-se a questão de ser acompanhada por boa performance ambiental: o que sucede quando se raciocina em ciclo de vida, isto é, quando se considera o dispêndio adicional de recursos (solventes, energia, etc.) incorridos na purificação pelo fornecedor do reagente purificado?

Por outro lado, a química laboratorial é frequentemente realizada com reagentes de pureza elevada, enquanto os processos industriais usam reagentes comerciais de menor qualidade. Por isso, quando se estuda no laboratório a química de base de um processo industrial é conveniente incluir experiências com os reagentes comerciais mais impuros que vão ser utilizados no fabrico em grande escala, para investigar até que ponto os resultados são válidos em regime industrial.

Em suma, este princípio complementa o anterior: este último pressiona os químicos académicos a "olhar para a frente", para o escalamento da síntese e desenvolvimento do processo, o presente a voltarem a "olhar para trás", reavaliando a química de base do ponto de vista industrial - em suma, apelam à prática do raciocínio circular caraterístico da postura sistémica.

\section{Princípio 21 - Procura (desenvolvimento e aplicação) de medidas de sustentabilidade do processo}

Deve-se tentar avaliar o melhor possível, quantitativamente, mediante métodos tanto quanto possível padronizados, o grau de sustentabilidade que possa ser obtido no processo industrial, após escalamento. Esta atividade é ainda incipiente no âmbito da QV, mas é de prever que adquira interesse crescente no futuro - o que passa por desenvolver e aplicar métricas de processo com abrangência lata (de verdura química e ambiental, de sustentabilidade, etc.), mas preferivelmente de implementação mais simples do que aquelas que são já usadas pelos engenheiros químicos. ${ }^{14}$ Neste contexto, deve merecer atenção o desenvolvimento de métricas holísticas. ${ }^{15}$

\section{Princípio 22 - Quantificação e minimização do uso de "utilidades"}

O uso das "utilidades" (água, eletricidade, vapor, etc.) é quase sempre completamente ignorado nos estudos laboratoriais, mas os químicos devem começar a pensar nas suas implicações. Por exemplo, o uso de água (para lavagem, arrefecimento, etc.) e de gases para obter atmosfera inerte (azoto, etc.) pode provocar o seu aparecimento em quantidades significativas nos efluentes. Outro exemplo: embora o uso como solvente de dióxido de carbono na forma de fluído supercrítico permita a substituição de solventes problemáticos, a sua compressão e manejamento consome quantidades elevadas de energia e pode significar custos proibitivos.

Os químicos laboratoriais devem passar a dar atenção ao uso das "utilidades" e sua minimização e, na medida do possível, proporcionar informação que permita avaliar as respetivas necessidades e custos ao longo do escalamento da síntese.

\section{Princípio 23 - Identificação de situações de incompatibilidade entre a segurança do processo e a minimização de resíduos}

Os objetivos da QV são múltiplos e, por isso, na prática, quando se procura aumentar a verdura dos processos, tem de se adotar frequentemente soluções de compromisso. Uma destas situações, previsivelmente vulgares, é a de não se poder trabalhar em condições ótimas para impedir a formação de resíduos e incorporar os átomos dos reagentes no produto, porque elas envolvem um acréscimo da insegurança do processo - podem conduzir a desastres, afectar o ambiente ocupacional, etc. Por exemplo, a oxidação parcial de hidrocarbonetos com oxigénio molecular (em vez de oxidantes clássicos, que são frequentemente problemáticos, ver o princípio 14) é muito apelativa sob o ponto de vista de melhorar a verdura da oxidação mas exige cuidado para evitar composições de misturas de oxigénio com hidrocarboneto e condições que possam originar explosões. Os químicos laboratoriais, no desenho da via de síntese a nível laboratorial, devem dar atenção à segurança do processo escalado e alertar para potenciais problemas, com vista à inclusão de medidas preventivas logo no início do desenvolvimento (segurança embutida, monitorização, etc.). Por outro lado, quando é necessário satisfazer dois critérios com efeitos opostos, ambos necessários para obter um processo adequado, o compromisso passa pela análise dos respetivos custos relativos - e a decisão, sendo de natureza económica, pode ser difícil, porque elusiva.

\section{Princípio 24 - Monitorização, registo e minimização dos resíduos produzidos na realização laboratorial da síntese}

O químico laboratorial deve dar atenção pormenorizada e quantitativa aos resíduos produzidos na síntese laboratorial e lutar pela sua minimização logo a esta escala. Mais precisamente, deve analisar o conjunto dos fluxos de resíduos libertados para o ar e a água, bem como aos sólidos, quer em experiências relativas a reações individuais, quer no que respeita à totalidade de reações da via de síntese, para o que é importante visualizar como um todo a química de base a usar num processo industrial.

\section{Discussão intercalar}

Segundo o seu proponente, a prática dos segundos 12 princípios da QV será o suprassumo da "demonstração direta e real da mentalidade verde do químico" - a prova cabal da sua atitude a favor da QV. ${ }^{3}$ Estes princípios, tal como os primeiros 12, por si sós, não são suficientes para garantir a montagem de processos verdes e implementar uma Indústria Química Verde - porque o bom cumprimento da cadeia de verdura (Figura 1) envolve fatores tecnológicos exteriores à Química, bem como outros (económicos, etc.), não contemplados nos princípios. No entanto, este segundo conjunto de princípios de QV merece atenção - porque permite um aumento da consciencialização 
dos químicos laboratoriais quer para os problemas de concretização de verdura à escala industrial, quer para a necessidade de definir áreas de investigação académica previsivelmente mais produtivas para este fim.

\section{RELAÇÕES ENTRE OS DOIS CONJUNTOS DE PRINCÍPIOS}

Para se conseguir verdura química com eficácia, é necessário que os princípios da QV sejam aplicados em conjunto, com atitude holística. Os princípios de cada um dos grupos têm intraligações entre si, havendo também interligações entre os princípios dos dois grupos, que devem ser consideradas na utilização. Nomeadamente, para se melhorar a verdura de uma síntese, não se podem aplicar os princípios um a um, isoladamente, sob pena de, quando se melhora a verdura quanto a um, se piorar quanto a outros - é preciso atender a eles como um todo, para o que se aconselha percursos de análise dos seus efeitos em ciclos iterativos, dentro de cada grupo e entre os dois, como ilustra graficamente a Figura 3.

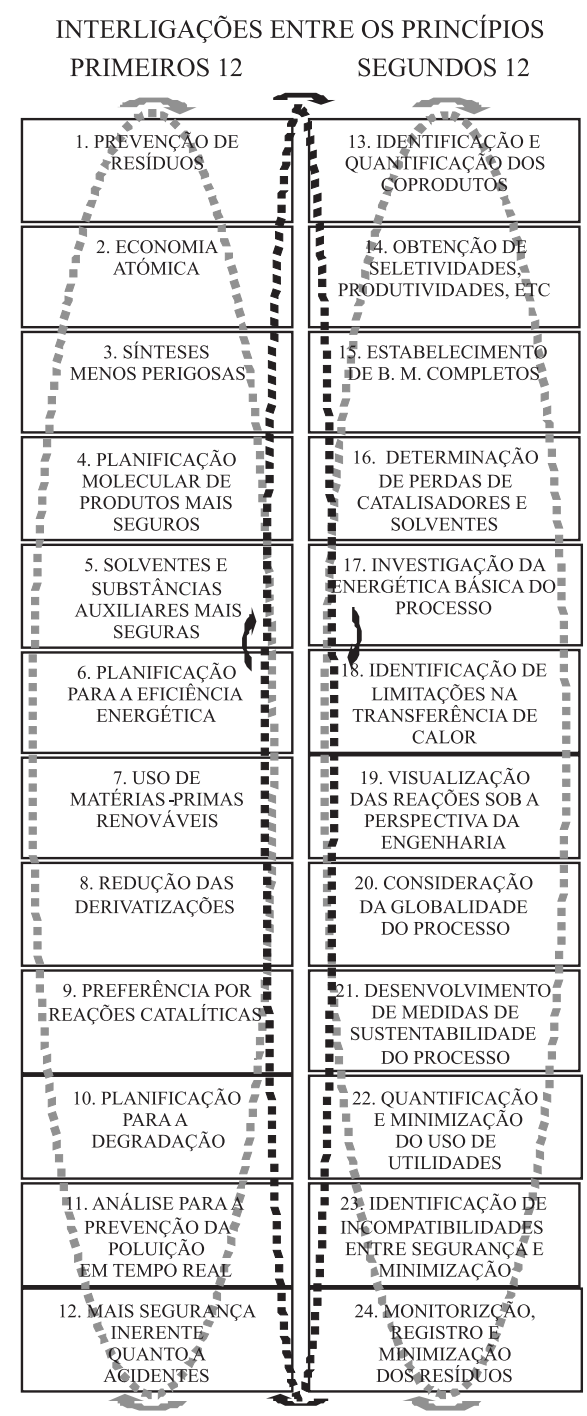

Figura 3. Para atender às interligações entre todos os princípios e concretizar a sua aplicação cabal e eficaz é necessário proceder a iterações (percursos indicados por setas) quer dentro dos dois grupos, quer entre eles

O problema global das interligações entre os 24 princípios é muito complexo, dada a variedade de situações encontradas na Química e a diferente natureza e alcance dos princípios, e não vai ser abordado aqui, porque alongaria muito o artigo - tanto mais que deve ser considerado em conjunto com outras questões relevantes sobre os princípios e sua utilização, por exemplo, a respetiva hierarquização e os aspetos importantes na prática da Química que não são contemplados neles. No entanto, vai caraterizar-se sumariamente as interrelações entre os dois conjuntos de princípios, para esclarecer as diferenças de postura que lhes servem de base.

A análise sobre as interligações que se segue foi feita dos primeiros para os segundos 12 princípios, por estes últimos serem mais particularizantes. Ao estabelecer as interligações, foram encontradas algumas dificuldades, nomeadamente: em primeiro lugar, as relações não são necessariamente simétricas - em certos casos, um princípio dos primeiros 12 "empurra” outro dos segundos 12, noutros casos um princípio deste último grupo "puxa" outro do primeiro; em segundo, como definir relações depende da formação e experiência pessoal de quem realiza a tarefa, podem aqui não ter sido identificadas todas assim, a análise não é garantidamente exaustiva.

Para facilitar a identificação das interligações, começou-se por agrupar os princípios de cada um dos conjuntos quanto à componente sistémica (matéria, energia e informação) a que estavam mais ligados, sendo os resultados apresentados na Tabela 1 (não foi possível classificar dois dos princípios - 12 e 20 - seguindo este critério, pois têm alcance abrangente). A tabela mostra que a grande maioria dos primeiros 12 princípios dizem respeito à matéria - à Química; nos segundos 12, os princípios "espalham-se" mais para a energia e informação, comprovando o facto de serem mais dirigidos ao sistema industrial - ao processo químico.

Tabela 1. Distribuição dos dois conjuntos de 12 princípios segundo as componentes sistémicas*

\begin{tabular}{lcc}
\hline & Primeiros 12 & Segundos 12 \\
\hline Matéria & $1-5,7-10$ & $13-16,22-24$ \\
Energia & 6 & $17-18,22$ \\
Informação & 11 & 19,21 \\
S/ classificação & 12 & 20 \\
\hline
\end{tabular}

*O princípio 22 (quantificação e minimização do uso de "utilidades") diz respeito quer às "utilidades" materiais (água, etc.), quer à energia, pelo que a sua entrada aparece duplicada.

A Tabela 1 serviu de ponto de partida para identificar as conexões por análise individual dos pares de princípios (cada princípio dos primeiros 12 foi sucessivamente emparelhado com os do segundo grupo). As interrelações foram classificadas em dois níveis, fortes ( $F$, as que foram identificadas imediatamente a partir das definições dos dois princípios emparelhados) e fracas (f, as que requereram análise mais aprofundada), mas esta classificação pode depender da experiência pessoal do agente classificador, ramo da Química que pratica, etc. Além disso, hierarquizar as "forças" das relações de cada princípio é mais fácil do que fazê-lo entre princípios diferentes, nomeadamente quando a natureza e alcance destes são diversos. Os resultados deste exercício são apresentados na Figura 4, listando-se no Quadro 2 as interligações fortes, correspondentes às setas grossas na Figura (no Quadro S1, material suplementar, apresenta-se uma lista de todas as interligações encontradas). No Quadro 2, antes de descrever cada interligação, apresenta-se a respetiva justificação (em itálico). A Figura 4 mostra como a rede de interconexões é intrincada, evidenciando que cumprir simultaneamente todos os princípios da QV pode ser uma tarefa espinhosa - e espelhando quão complexa é a verdura química. A figura confirma o espalhamento das componentes sugerido pela Tabela 1 - evidenciado por um maior emaranhamento das linhas no lado dos segundos 12 princípios. Este acentua-se nos 
princípios 19 (visualizar as reações sob a perspetiva dos engenheiros químicos) e 21 (desenvolver medidas para a sustentabilidade do processo), o que tem a ver com o alcance mais vasto e difuso destes. Foram identificadas 17 interligações fortes e 22 fracas, num total de 39, para um máximo possível de $144(=12 \times 12)$, sendo portanto a conetividade global de $27 \%$ (no entanto, a Figura 4 mostra que a conetividade é bastante heterogénea).

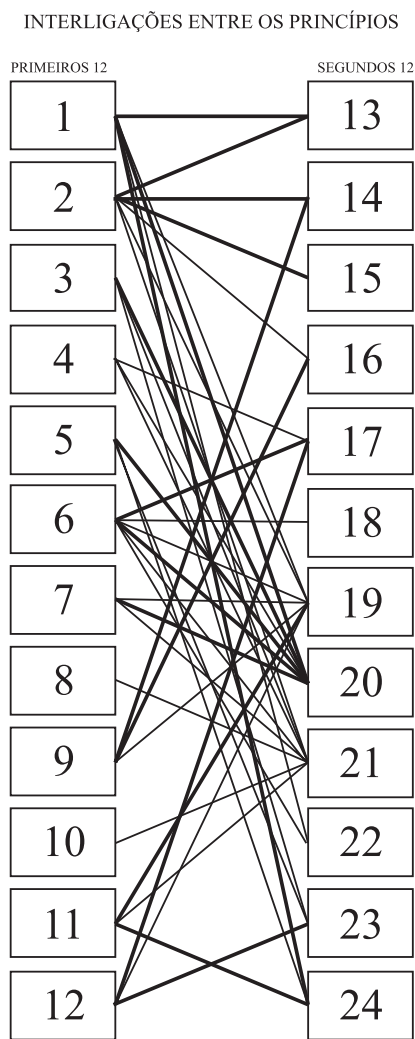

Figura 4. Interligações entre os primeiros e os segundos 12 princípios (Fortes, setas grossas; fracas, setas finas)

\section{DISCUSSÃO FINAL}

Os primeiros 12 princípios da QV têm sido muito úteis na divulgação desta e proporcionam um enquadramento para uma primeira avaliação simples da verdura de reações, vias de síntese, etc., e comparação de verdura de alternativas possíveis para cumprir um dado objetivo, com vista a escolher a mais aceitável quanto a impactos ambientais. No entanto, traduzem fundamentalmente a atitude sensata e louvável de químicos bem intencionados que pretendem reformatar a Química para eliminar os seus impactos negativos (a QV chegou a ser apresentada como um "imperativo moral" ${ }^{15}$ ), enquanto a atividade da Química real é muito mais complexa. Em consequência, a utilização destes princípios tem limitações diversas, por exemplo, por um lado, são algo genéricos e distantes da realidade industrial -ignoram ou, pelo menos, não explicitam, caraterísticas importantes da Química do mundo real, por exemplo, a necessidade de usar ferramentas de avaliação de largo alcance (ciclo de vida), de garantir viabilidade económica, de proporcionar uma adequada inserção societal da Química, etc.; por outro, são prescrições qualitativas - e a avaliação cabal da verdura exige o cálculo de métricas quantitativas de verdura, ${ }^{8}$ preferivelmente holísticas. ${ }^{16}$ Em consequência, as respetivas prescrições podem ser equívocas - por exemplo, o princípio 7 prescreve o uso de matérias-primas renováveis em termos gerais, mas quando se considera o ciclo de vida de obtenção de biomassa por via agrícola, a sua avaliação por métricas é muito complexa e o princípio torna-se problemático. Também, a preferência por reações catalíticas prescrita pelo princípio 9 tem de ser pesada pelos impactos da preparação do catalisador e da sua deposição final - o ciclo de vida do catalisador pode ser suficientemente problemático para subverter a escolha da via catalítica. Aliás, algo de semelhante vale para outras substâncias auxiliares, solventes, etc. por isso é que a aplicação da análise de ciclo de vida aos compostos e processos químicos é tão espinhosa: envolve quase sempre vários ciclos de vida laterais emaranhados com o principal, o que implica muitas dificuldades na elaboração deste (mais uma consequência inevitável da complexidade intrínseca da Química!).

Os segundos 12 princípios têm por base uma atitude mais pragmática, são mais dirigidos à implementação industrial da Química,

Quadro 2. Interligações fortes entre os primeiros 12 e os segundos 12 princípios da QV*

1. PREVENÇÃO DE RESÍDUOS 4 . ...

13. Identificação e quantificação de coprodutos

Para se poder prevenir a formação de resíduos é necessário o seu reconhecimento

A prevenção de coprodutos das reações de síntese...exige atenção à sua formação, nomeadamente para permitir prever, à partida do escalamento, a quantidade destes resíduos, inevitáveis porque estequiométricos, e procurar a sua minimização por alteração da via de síntese

20. Consideração da globalidade do processo industrial

Os resíduos formados dependem da química de base adotada para o processo

A prevenção de resíduos... passa por considerar o processo industrial em globo para procurar uma via de síntese (reações requeridas, condições de realização, etc.) adequada à sua minimização

$\ldots$ 24. Monitorização, registo e minimização do resíduos

Ambos os princípios têm como objetivo a prevenção da formação de resíduos

A minimização dos resíduos no processo industrial...é facilitada pela aquisição de conhecimento sobre eles no laboratório e seu registro, com esforço simultâneo para conseguir a respetiva minimização

\section{ECONOMIA ATÓMICA $4 \ldots$}

$\ldots \downarrow 13$. Identificação e quantificação de coprodutos

A economia atómica diminui quando aumenta o número de átomos perdidos nos coprodutos

A maximização da economia atómica...exige a minimização da perda de átomos, o que passa por dar atenção aos coprodutos

... 14. Obtenção de seletividades, produtividades, etc.

A economia atómica depende dos valores das métricas de massa

A maximização da economia atómica...passa por obter valores de variadas métricas, informativas sobre o destino dos átomos aportados pelos reagentes

$\ldots 4$ 15. Estabelecimento de balanços materiais (BM) completos

A inclusão preferencial no produto dos átomos aportados pelos reagentes é confirmada pelos BM

A avaliação da precisão (e confiança no valor) da economia atómica...é proporcionada por BM completos realizados a partir dos caudais e composições das entradas e saídas 
Quadro 2. continuação

\begin{tabular}{|c|}
\hline 3. SÍNTESES MENOS PERIGOSAS \• \\
\hline $\begin{array}{l}\ldots 4 \text { 20. Consideração da globalidade do processo industrial } \\
\text { A perigosidade (toxicidade, etc.) depende da química de base adotada para o processo } \\
\text { A obtenção de benignidade...passa por considerar o processo industrial em globo para procurar uma via de síntese adequada para concretizar a minimização } \\
\text { da perigosidade }\end{array}$ \\
\hline 5. SOLVENTES E SUBSTÂNCIAS AUXILIARES MAIS SEGURAS $\leadsto \ldots$ \\
\hline $\begin{array}{l}\ldots \text { 20. Consideração da globalidade do processo industrial } \\
\text { O uso e escolha de solventes, etc., dependem da química de base adotada para o processo } \\
\text { A minimização do uso dos solventes e substâncias auxiliares e a maximização da respetiva segurança... passam por escrutinar o processo industrial em globo }\end{array}$ \\
\hline 6. PLANIFICAÇÃO PARA A EFICIÊNCIA ENERGÉTICA $\leadsto$... \\
\hline $\begin{array}{l}\ldots 4 \text { 17. Investigação da energética básica do processo } \\
\text { Ambos os princípios têm como preocupação a energética do processo } \\
\text { A obtenção de eficiência energética...exige o conhecimento da energética básica (entalpia) das reações para permitir a planificação do processo com vista à }\end{array}$ \\
\hline
\end{tabular}
recuperação de calor e minimização do dispêndio de energia

$\ldots \triangleleft 20$. Consideração da globalidade do processo industrial

Uma fração apreciável do calor gasto nos processos químicos ocorre em operações unitárias

A maximização da eficiência energética...passa por considerar o processo industrial em globo para explorar oportunidades de minimizar o dispêndio e maximizar a recuperação de calor

\section{USO DE MATÉRIAS-PRIMAS RENOVÁVEIS 《 ...}

$\ldots 4$ 20. Consideração da globalidade do processo industrial

As matérias-primas que podem ser usadas nos processos dependem da natureza destes

A escolha de matérias-primas renováveis...passa por considerar o processo industrial em globo para explorar oportunidades de este ser montado com reagentes de origem renovável

9. PREFERÊNCIA POR REAÇÕES CATALÍTICAS 4 ...

$\ldots$ ‥ 14. Obtenção de seletividades, produtividades, etc

A exequabilidade da preferência por reações catalíticas exige a existência de catalisadores eficazes

A avaliação da eficiência de reações catalíticas...tem de ser comprovada por valores da seletividades e métricas de produtividade

$\ldots \hookrightarrow$ 16. Determinação das perdas de catalisadores e solventes

A eficácia do uso de catalisadores passa pela minimização das suas perdas

A performance de reações catalíticas...tem de ser comprovada pela determinação das perdas de catalisadores

11. ANÁLISE PARA A PREVENÇÃO DA POLUIÇÃO EM TEMPO REAL 4 . ...

$\ldots \triangleleft 19$. Visualização das reações sob a perspetiva dos engenheiros químicos

A análise em tempo real permite melhorar o controlo do processo

A análise para a prevenção da poluição em tempo real...está envolvida no controlo do processo industrial, uma das tarefas da responsabilidade dos engenheiros químicos

$\ldots \triangleleft 24$. Monitorização, registo e minimização do resíduos

Ambos os princípios têm como preocupação a minimização de poluentes e resíduos

A análise para a prevenção da poluição em tempo real...é facilitada pela aquisição de conhecimento e seu registo, no laboratório, sobre os poluentes e resíduos

12. MAIS SEGURANÇA INERENTE QUANTO A ACIDENTES 4 ...

$\ldots \triangleleft 17$. Investigação da energética básica do processo

A segurança exige um controlo eficaz da libertação de calor nas reações exotérmicas

A segurança inerente ...usa o conhecimento da energética básica das reações da via de síntese para prevenir acidentes decorrentes da libertação de calor

$\ldots \downarrow 23$. Identificar incompatibilidades entre segurança e minimização de resíduos

Ambos os princípios têm como preocupação a segurança

A obtenção de segurança inerente...pode significar a necessidade de operar fora das condições ótimas e exigir sacrifícios quanto à minimização de resíduos

* Os princípios 4, 8 e 10 não foram incluídos por não se terem identificado interligações fortes (apenas fracas)

incorporam conhecimentos aprendidos e usados trivialmente pelos engenheiros químicos ao longo do século $\mathrm{XX}^{17}$ - e procuram colmatar algumas das limitações dos primeiros 12 princípios, embora só parcialmente o consigam (nomeadamente, por exemplo, mantêm-se as referidas no parágrafo anterior).

Quando se consideram as interligações entre os dois conjuntos de princípios da QV, verifica-se que estas são numerosas e constituem uma rede densa e intricada, o que faz sentir bem a complexidade da verdura química - e as dificuldades que se deparam ao avanço da química para a QV.

\section{CONCLUSÕES}

A aplicação dos segundos 12 princípios pelos químicos laboratoriais, só por si, não garante desde logo o desenvolvimento posterior, à escala industrial, de processos químicos verdes e o cumprimento completo da cadeia de verdura. No entanto, eles ajudarão os químicos laboratoriais a fazer incidir a sua atenção em áreas de investigação mais produtivas quanto à QV e a seleccioná-las precocemente como merecedores de atividade prioritária - isto é, favorecem uma atitude proativa dos químicos com respeito à QV. Além disso, o seguimento destes princípios pode proporcionar muita informação útil aos químicos e engenheiros químicos que procedem à escolha dos produtos (isto é, dos compostos a fabricar) e se ocupam do desenvolvimento dos processos industriais para a sua preparação em grande escala - já que o alargamento de conhecimento no início do seu trabalho facilita a maximização da verdura ao longo dele. No entanto, não se pode esquecer que as decisões de se adotarem, ou não, novos 
processos químicos industriais resultantes da investigação dirigida à QV, envolvem componentes de natureza tecnológica e económica que caem fora do domínio da química de base, mas que também são importantes para a eficiência global da Indústria Química e das suas caraterísticas como suporte da sustentabilidade. Tais fatores são considerados no âmbito da Engenharia Química Verde, que tem de ser usada conjugadamente com a QV para se implementar processos industriais verdes - e se progredir incrementalmente ao longo da cadeia de verdura para se chegar a uma Indústria Química Verde (Figura 1). A ligação da QV como a Ecologia Industrial também não pode ser esquecida. ${ }^{18}$ Em suma, a integração da Química com a tecnologia química é muito importante para a prossecução e desenvolvimento da QV e da sustentabilidade, e embora se continue a apelar aos primeiros 12 princípios para a fundamentar, ${ }^{19}$ pode ser melhor concretizada se se atender também ao segundo conjunto de princípios.

A terminar, deve-se ainda recordar, mesmo incorrendo em repetição, ${ }^{9}$ que o uso dos princípios da QV deve ser feito com postura sistémica, em que eles são atendidos e aplicados globalmente, como um todo, mas este requisito contrasta com a formação tradicionalmente reducionista dos químicos académicos - sendo esta, possivelmente, a maior barreira à conceção da síntese verde (e à prática da $\mathrm{QV}$ em geral). Por isso, é importante que o ensino da Química passe a incluir formação em ciência sistémica.

\section{MATERIAL SUPLEMENTAR}

Está disponível em http://www.quimicqnova.sbq.org.br, na forma de arquivo PDF e com acesso livre, o seguinte material: texto com detalhes sobre a influência da escala na dissipação de calor em reactores e Quadro 1S com lista completa das interações entre os dois conjuntos de 12 princípios da QV incluídas na Figura 4.

\section{REFERÊNCIAS}

1. Anastas, P. T.; Warner, J. C.; Green Chemistry - Theory and Practice, Oxford UP: Oxford, 1998, p. 30.

2. Lenardão, E. J.; Freitag, R. A.; Dabdoub, M. J.; Batista, A. C. F.; Silveira, C. C.; Quim. Nova 2003, 26, 123; Prado, A. G. S.; Quim. Nova
2003, 26, 738; Vichi, F. M.; Mansor, M. T. C.; Quim. Nova 2009, 32, 757; Farias, L. A.; Fávaro, D. I. T.; Quim. Nova 2011, 34, 1089.

3. Winterton, N.;, Green Chem. 2001, 3, G73.

4. Winterton, N.; Clean Techn. Environ. Policy 2001, 3, 62; 2003, 5, 8; 2003, 5, 154.

5. São ignorados, por exemplo, nos textos de: Ahluwalia, V. K.; Green Chemistry - Environmentally Benign Reactions, CRC Press: Boca Raton, 2008; Lancaster, M.; Green Chemistry - An Introductory Text, $2^{\text {nd }}$ ed., RSC Publishing: Cambridge, 2010.

6. O seguinte texto limita-se a referi-los no prefácio: Matlack, A. S.; Introduction to Green Chemistry, $2^{\text {nd }}$ ed., CRC Press: Boca Raton, 2010, p. vii.

7. A química da síntese do carbarilo, que esteve na base do desastre de Bhopal (1984), proporciona um exemplo incisivo da natureza não linear da Química, ver Machado, A. A. S. C.; Química - Bol. S. P. Q. 2010, $118,41$.

8. Lapkin, A.; Constable, D., eds.; Green Chemistry Metrics; Wiley: Chichester, 2008.

9. Machado, A. A. S. C.; Quim. Nova 2011, 34, 1291 e 1862.

10. Kim, S.; Overcash, M.; J. Chem. Technol. Biotechnol. 2003, 78, 995.

11. Wernet, G.; Mutel, C.; Hellweg, S.; Hungerbuhler, K.; J. Ind. Ecol. 2011, $15,96$.

12. Clausen III, C. A.; Mattson, G.; Principles of Industrial Chemistry, Wiley-Interscience: Nova Iorque, 1978, p. 135.

13. Starkie, A; Rowe, S.; Chem. Brit. 1966, 32, 34

14. Allen, D. T.; Shonnard, D. R.; Green Engineering - Environmental Conscious Design of Chemical Processes, Prentice Hall: Upper Sadddle River, 2002.

15. Hancock K. G.; Cavanaugh, M. A. Em Bening by Design-Alternative Synthetic Design for Pollution Prevention; Anastas, P. T.; Farris, C. A., eds.; ACS Symposion Series 577, ACS: Washington, 1994, chap. 2.

16. Ribeiro, M. G. T. C.; Costa, D. A.; Machado, A. A. S. C.; Quim. Nova 2010, 33, 759; Ribeiro, M. G. T. C.; Machado, A. A. S. C.; J. Chem. Educ. 2011, 88, 947.

17. Lange, J. P.; ChemSustChem 2009, 2, 587.

18. Machado, A. A. S. C.; Quim. Nova 2011, 34, 535.

19. Anastas, P. T.; ChemSustChem 2009, 2, 391. 